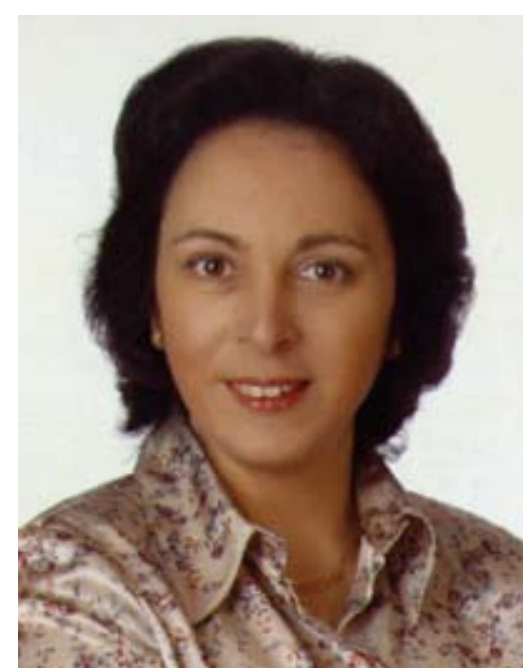

La carta de un estudiante internacional que se recibió en el Departamento de Español como Segunda Lengua del Recinto Santo Tomás de Aquino de PUCMM introduce un breve análisis de los siguientes aspectos: el significado del "ser intercultural", la relación entre la interculturalidad y el pensamiento de la Enciclíclica del papa Juan XXIII, la importancia del conocimiento intercultural en el mundo universitario dominicano y su aplicación en la sociedad actual.

ECOS DESDELAS FACULTADES

\title{
INTERCULTURALIDAD: UNA ASIGNATURA PENDIENTE EN EL CURRÍCULO ACADÉMICO
}

\section{María Virtudes Núñez Fidalgo*}

Con el mayor respeto, permítame que me presente. Me llamo K. L. y vivo en Denver, Colorado. Soy estudiante de Ciencias Políticas en la Universidad de Clark, Atlanta en Georgia. También estudio español. He venido aquí a República Dominicana, a estudiar en el extranjero, para aprender español.

Al igual que la mayoría de la gente, mis razones para querer aprender español no son para decir "hablo una segunda lengua" o para llegar a estar entre la élite. Simplemente quiero aprender español, me interesa la riqueza de su herencia, sus valores, sus creencias, la riqueza cultural que poseen todos los hablantes nativos hispanos. La gente que habla español tiene una gran cantidad de conocimientos acerca de muchas cosas. Para captar ese conocimiento, necesito aprender la lengua. De todos modos, yo sólo estoy siguiendo mi corazón.

\section{Con respeto, K. L.}

Hace algún tiempo recibimos en nuestro departamento esta breve comunicación escrita por una estudiante anónima de Español como Segunda Lengua. Hemos querido iniciar esta reflexión con ese ejemplo porque forma parte de un aprendizaje intercultural desarrollado a lo largo de más de media vida compartiendo en varios países con estudiantes internacionales. Ese sentido de lo intercultural es el principal motor intelectual que anima nuestra tarea cotidiana en el Recinto Santo Tomás de Aquino durante los últimos diez años.

El estudiante habla en su carta de "estudiar en el extranjero". Todos conocemos esta sencilla expresión. Cada una de esas palabras encierra la vivencia plena, la oportunidad de renovación por medio de un gran esfuerzo y la presencia de un andamiaje que usualmente no está exento de sufrimiento. El paso de una cultura a otra tiene un coste que va mucho más allá de lo meramente económico. El hecho de asumirse como un ser intercultural, implica mirarse en el difícil espejo del extrañamiento del ser, que se mira a sí mismo con ese inexplicable sentimiento que le hace verse como "otro", "diferente" porque participa del conocimiento y de la experiencia vivida en el seno de dos culturas, pero también realiza un tremendo esfuerzo intelectual, emocional y espiritual que de alguna manera lo separa de su pasado individual. "El otro", el que dice "he venido aquí, a República Dominicana", se obliga a sí mismo a abandonar su confortable sentido de pertenencia al grupo, a cuestionar los propios valores culturales heredados que habían sido aceptados de manera natural, sin preguntas; a romper costumbres con las que se identifica y en las que siempre ha creído.

El ser intercultural deberá abandonar de maneraconscientemuchos de los parámetros que habían sido aceptados, de forma acrítica, durante el proceso de aprendizaje realizado durante la niñez para entrar en esferas de

\footnotetext{
" Doctora en Filología Hispánica por la Universidad Complutense de Madrid. Directora del Departamento de Español como Segunda Lengua en la Pontificia Universidad Católica Madre y Maestra, Recinto Santo Tomás de Aquino.

${ }^{1}$ Este concepto está bien desarrollado en la literatura del siglo XX, a través de los autores del existencialismo. La metamorfosis deF. Kafka y El extranjero de A. Camus son dos novelas donde se pueden ver, desde distintas perspectivas, a personajes sometidos a un proceso de extrañamiento de sí mismos. Por otra parte, una aplicación más cercana a la pedagogía la encontramos en el artículo de tres profesores de la Universidad de Almería: Checa Olmos, F., Checa Olmos, J.C., Arjona Garrido, A.: El extrañamiento cultural en espacios migratorios. La juventud andaluza ante el reto de la multiculturalidad. Rev. Migraciones internacionales, vol. 4, núm. 1, enero-junio 2007 págs. 111-140. Disponible en Internet: http://dialnet.unirioja.es/servlet/articulo?codigo=2380409\&orden=136559\&info=link
} 
comportamientos que muchas veces no son mejores ni peores, sino diferentes. Es así como se provoca en el interior de las personas un sentimiento de orfandad cultural, un vacío emocional y espiritual generado por el desencuentro de costumbres y tradiciones, por la falta (no pérdida, sino inexistencia) de aquellos bienes sagrados no tangibles, no pagables, inherentes a la historia familiar y la vivencia intrapersonal.

En su esencia, el ser intercultural está llamado a convertirse en una fuente de luz entre sus congéneres. Posee la capacidad del migrante, viaja -a veces sin pensarlo- no por lo que tiene 0 con lo tiene, sino con lo que sabe, con la inexcusable certeza de la experiencia vivida. Se reconoce a sí mismo dentro de sus limitaciones, dentro de su relatividad cultural. Además, se convierte en portador de sus tradiciones, en constructor de lo suyo dentro de lo del otro, en partícipe de lo del otro y destructor de lo suyo. La contradicción adquiere una nueva dimensión en el conocimiento intercultural y pasa a formar parte de una concepción, donde la verdad absoluta deja su lugar a un conjunto de articulaciones movibles, como si fueran rompecabezas que juegan solos a hacerse y deshacerse dentro de un universo de movimientos, que no siempre deben analizarse desde el pensamiento aprendido en la filosofía clásica de Occidente.

En este marco, donde las dinámicas de lo humano condicionan el proceso de aprendizaje en jóvenes y adultos, La Encíclica del Papa Juan XXIII Sobre el reciente desarrollo de la cuestión social a la luz de la doctrina cristiana ilumina al intelectual universitario con una organización modélica para manejar las redes del pensamiento intercultural, a través deun proceso que sesintetiza en tres fases: "Ver, juzgar y obrar". Este modelo de acción está contenido en la sección titulada "Necesidad de organización de la acción social católica"2 y se detalla en los apartados 236, 237, 238 y 239.

"Ver" es sentir con el cuerpo, el intelecto y el espíritu, la compleja realidad de la otra cultura. "Ver" necesita de un aprendizaje que provea de las habilidades necesarias para disfrutar de la inefabilidad del encuentro. "Ver" es saber buscar la alteridad, prepararse para encontrar al otro-que-es-diferente, en un ambiente de silencioso asentimiento comprensivo, similar al que se produce cuando se encuentra al otro-que-es-igual, porque ha nacido y crecido en la misma cultura.

Después, "Juzgar". Juzgar, pero sólo una vez que se ha visto, que se ha vivido, que se ha examinado cuidadosamente el complejo entramado que condiciona el pensamiento, la actitud, la historia del otro. Se trata de reconocer, en un largo proceso de reflexión crítica, la realidad del que es diferente para revisarla y mejorarla en lo que sea posible, siguiendo el sentido cristiano.

Juzgar es un ejercicio delicado que debe realizarse dedicándole el tiempo necesario y una atención cuidadosa para no caer en la crueldad del prejuicio. Encierra en sus dominios el poder de la exclusión, con la terrible consecuencia de la discriminación y debe ser ejercido de una forma (la Encíclica también lo dice) profundamente responsable. Quien juzga, sin duda, se erige en juez y lo más seguro es que, en este caso, el juicio siempre adolezca de un porcentaje de error puesto que suele suceder que se es 'juez y parte.' No olvidemos que el prefijo 'inter' contiene en

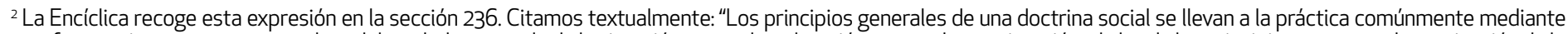

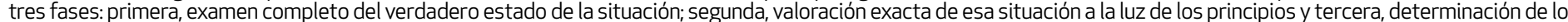

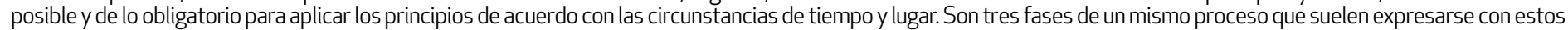
tres verbos: ver, juzgar y obrar".

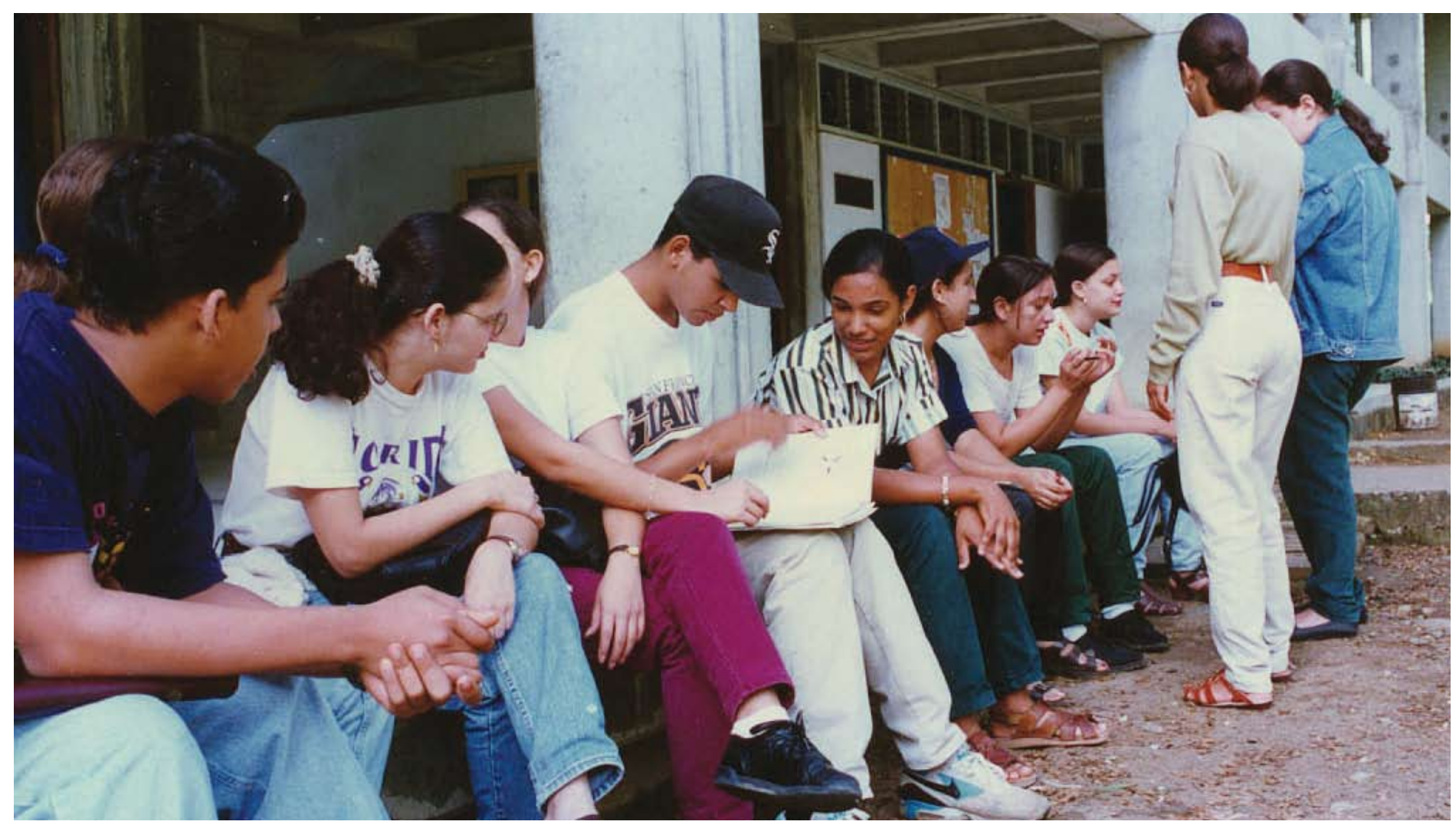


su significado un valor de participación en ambas culturas que limita la objetividad del juicio certero.

De todos modos, la Encíclica refiere este derecho con nitidez. Nosotros, desde la experiencia obtenida a través de los años compartidos con estudiantes extranjeros, recomendamos que sea ejercido con la generosidad que otorga la amistad solidaria. Un juicio crítico que contribuye a mejorar al otro en su condición es un bien social. Pero el juicio que sirve para rentabilizar el desprecio y socavar la autoestima del que está en condición inferior, por ser migrante de otra cultura, trae como consecuencia una seria erosión de la calidad de vida, del sentimiento de bienestar y debilita las relaciones en las dos comunidades: la de origen, impotente por saber que su hijo o hija no ha sido aceptado en ese nuevo entorno social y la de destino, incapaz de darle cabida con dignidad o de responder a sus expectativas humanas.

Y por último, obrar. La Encíclica se refiere a este punto con una breve aclaración "determinación de lo posible y de lo obligatorio para aplicar los principios de acuerdo con las circunstancias de tiempo y lugar". En nuestra lectura cotidiana de la prensa dominicana, observamos el incremento de conflictos interculturales, similares a los que se producen en otros países donde la diversidad cultural tiene un peso significativo en la base demográfica de su ciudadanía.
Uno de estos conflictos gira alrededor de la reivindicación del reconocimiento y el respeto a los derechos y la identidad de grupos minoritarios dentro de este país. Se suceden situaciones que contribuyen a sustituir la vieja ideología de la homogeneidad cultural por enfoques que atienden a lo diverso, lo diferente. Una manifestación reciente de tales conceptos se encuentra en la escena sociopolítica del país con el lanzamiento de un partido político bi-cultural. Otro aspecto relacionado con las situaciones mencionadas se refiere a la representación del derecho a la igualdad racial, como parte fundamental de la dominicanidad, problematizada por medio de acusaciones de racismo realizadas en distintos foros internacionales de gran impacto a nivel global. El manejo correcto de situaciones como las que acabamos de exponer difícilmente puede ofrecer la posibilidad de una solución satisfactoria para todos los implicados.

Pero lo que a nosotros nos interesa, como intelectuales y docentes universitarios, es recoger el reto que la sociedad nos lanza desde la realidad circundante; interpretar los signos de nuestro tiempo para encontrar respuestas que proporcionen una mejor calidad y nivel de vida para todos. Nuestra exigente sociedad del conocimiento, en la que nos ha tocado vivir, desea que le enseñemos lo que todavía no hemos terminado de aprender.

Tradicionalmente, en su dimensión formativa, la educación formal dominicana ha permanecido al margen de la interculturalidad.

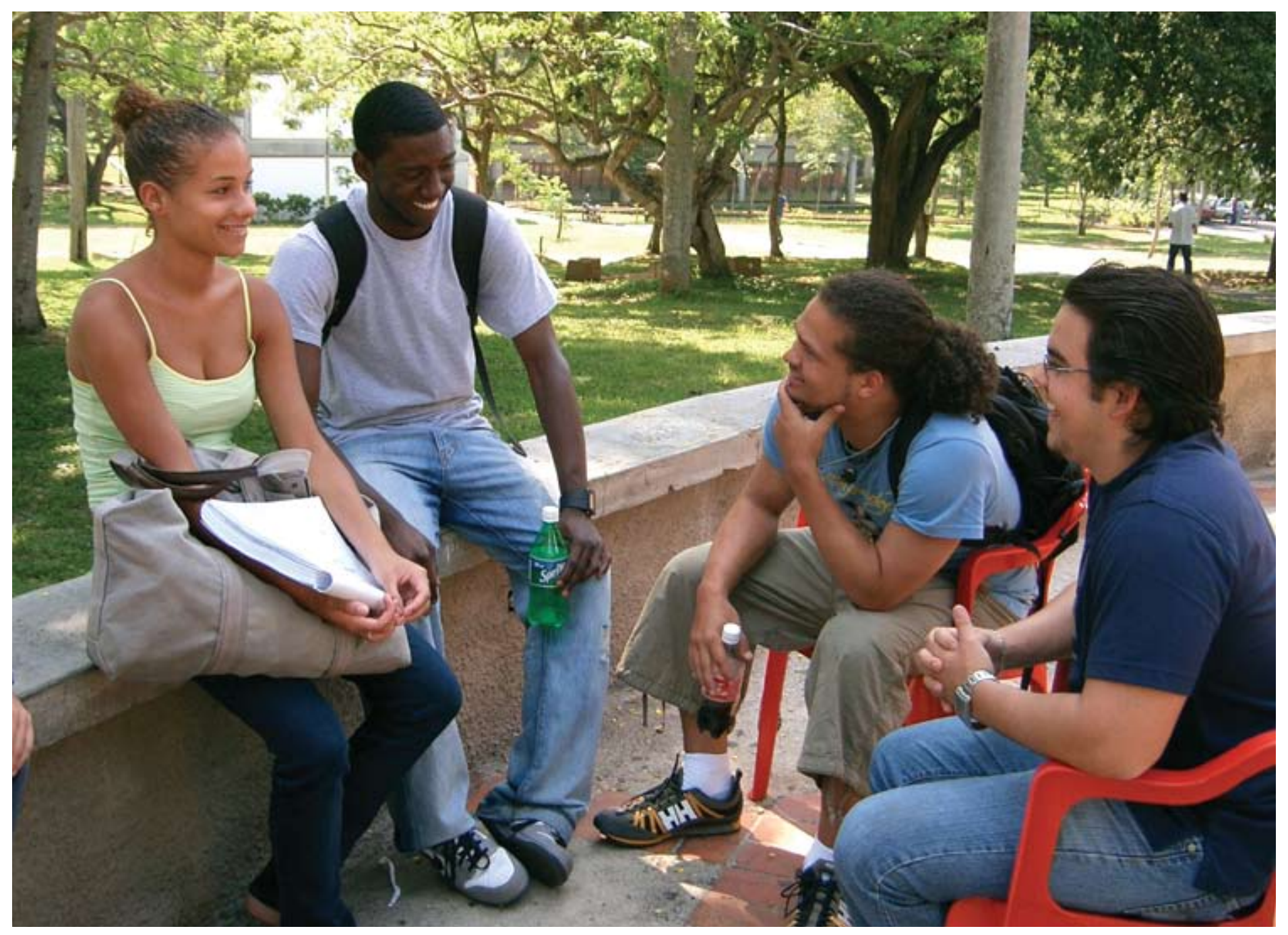


Entendemos que este hecho viene a incidir en el incremento significativo de actuaciones torpes y sin sentido, por parte de profesionales que no han recibido formación adecuada en el manejo de conflictos interculturales y en la solución de problemas originados por una realidad bicultural interpretada desde la óptica del conflicto y no desde la oportunidad del diálogo. La falta de formación intercultural ha traído decepción, rechazo, más ignorancia, incomprensión, respuestas débiles y dispersas por parte de funcionarios, empresarios e intelectuales ante situaciones como las arriba mencionadas.

Por este motivo, pensamos que la inclusión en el medio universitario dominicano de materias dedicadas al conocimiento intercultural y bicultural es una necesidad urgente, a la que hay que responder sin demora con la creación de programas académicos que vayan más allá de la simple capacitación en el manejo de segundas y terceras lenguas. Los profesionales dominicanos del futuro no pueden quedar al margen de este conocimiento imprescindible, del que deben hacer uso una vez que salen del dominio académico universitario.

En los distintos campus de PUCMM, observamos cada semestre el crecimiento de la presencia multicultural protagonizada por los estudiantes y el personal docente. En tal sentido, nos sentimos orgullosos ante el éxito obtenido por los estudiantes dominicanos en los programas internacionales de pre-grado y postgrado. Así mismo, el fuerte crecimiento en la demanda de carreras universitarias, que implican el desarrollo de relaciones profesionales entre personas procedentes de distintos países, como Hotelería y Turismo, Administración de Empresas, Negocios Internacionales y Comunicación Social, entre otras, confirma el hecho de que el camino del futuro se fundamenta en el conocimiento del otro desde una sistematización del pensamiento intercultural.

La sociedad dominicana, inmersa en las complejas redes de relaciones internacionales, ha sido y será víctima de fuertes presiones ejercidas desde el exterior que responden a intereses ajenos al bienestar de este país. Tales intereses afloran de forma esporádica para opacar la imagen de República Dominicana en el exterior.

Pero nosotros estamos empeñados en hacer crecer el frondoso árbol de la tolerancia. Trabajemos con ilusión para formar profesionales resueltos a manejar adecuadamente las múltiples vertientes de lo intercultural; a preparar funcionarios capaces de elaborar propuestas argumentadas en discursos que se hagan oír en los grandes foros de la globalización; equipos empresariales conducidos por gerentes afines al trabajo basado en el consenso. En fin, actores sociales que puedan proyectar políticas incluyentes en todos los órdenes del país.

\section{Referencias bibliográficas}

Gimeno Sacristán, J. (2001). Educar y convivir en la cultura global. Madrid: Morata

Gudykunst, W. B. \& Yun Kim, Y. (1997). Communicating with strangers. New York: MacGraw Hill.

Mater et Magistra. Sobre el reciente desarrollo de la cuestión social a la luz de la Doctrina Cristiana. Carta encíclica de Santidad Juan XXIII, extraído el 25 de abril de 2008, de http://www.es.catholic.net/biblioteca/libro.phtml?consecutivo=171\&capitulo=2424 Ong, A. (1999). Flexible Citizenship, the cultural logics of transnationality. North Carolina: Duke University Press.

O'Sullivan, K. (1994). Understanding ways: Communicating Between Cultures. Sydney: Hale \& Iremonger Pty Limited.

VVAA. 2003. Educación para la no discriminación, un diálogo con lo diverso. Centro Cultural Poveda. República Dominicana. 